\section{Studies on Chicken Actomyosin}

By J. M. Jones. (Agricultural Research Council Food Research Institute, Colney Lane, Norwich NOR 70F, U.K.)

There is evidence that the physical properties of actomyosin may vary depending on the physiological state of the muscle from which it was isolated, although the factors responsible for such variation have not been fully elucidated. A comparative study has been made of certain properties of chicken breast actomyosin isolated from pre-rigor (fresh) muscle and muscle taken from whole birds that have been held (aged) at $25^{\circ} \mathrm{C}$ after death.

The activity of the $\mathbf{M g}^{2+}$-stimulated adenosine triphosphatase of 'fresh' actomyosin decreased as the ionic strength of the test solution was increased, whereas the actomyosin $\mathrm{Mg}^{2+}$-stimulated adenosine triphosphatase obtained from muscle 'aged' for $2-4 \mathrm{~h}$ at $25^{\circ} \mathrm{C}$ was less sensitive to inhibition by potassium chloride. If the inhibition by potassium chloride of $\mathrm{Mg}^{2+}$-stimulated adenosine triphosphatase activity of rabbit actomyosin was due to the displacement of $\mathrm{Mg}^{2+}$ by $\mathrm{K}^{+}$from binding sites on the actin-myosin complex; as suggested by Nihei, Morris \& Jacobsen (1966), then the observations made in the present study might suggest that $\mathrm{Mg}^{2+}$ was not so readily lost in the case of actomyosin from 'aged' chicken muscle.

Superprecipitation (measured by the method of Ebashi, 1961) of actomyosin from 'aged' muscle was rapid and only occasionally was a clear short phase observed in the presence of $75 \mathrm{~mm}$-potassium chloride, whereas actomyosin from 'fresh' muscle was superprecipitated at a much lower rate and exhibited a clearing phase in the presence of $50 \mathrm{~mm}$ - and $75 \mathrm{~mm}$-potassium chloride.

It was found that the rate of superprecipitation of actomyosin from 'fresh' muscle was greater at $10 \mathrm{mM}-\mathrm{Mg}^{2+}$ than at $2.5 \mathrm{mM}-\mathrm{Mg}^{2+}$, whereas in the case of muscle 'aged' at $25^{\circ} \mathrm{C}$ for $2 \mathrm{~h}$ the rate of superprecipitation of the actomyosin was greater at $2.5 \mathrm{~mm}-\mathrm{Mg}^{2+}$ than at $10 \mathrm{~mm}-\mathrm{Mg}^{2+}$.

The acceleration of superprecipitation of actomyosin from 'aged' muscle suggests that the actinmyosin interaction may have been strengthened or that the content of a regulatory protein has been altered in these preparations. Further, changes of this kind might also be responsible for the observed decreased inhibitory effect of potassium chloride on the $\mathrm{Mg}^{2+}$-stimulated adenosine triphosphatase activity of actomyosin from 'aged' chicken breast muscle.

Ebashi, S. (1961). J. Biochem., Tokyo, 50, 236.

Nihei, T., Morris, M. \& Jacobsen, A. L. (1966). Archs Biochem. Biophys. 113, 45.
An Improved Method for the Electrophoresis of Enzymes using a Polyacrylamide-Starch Gel

By B. H. Parkin (introduced by C. W. Parr). (Metropolitan Police Forensic Laboratories, 2 Richbell Place, London WC1N 3LA, U.K.)

A thin (1 mm-thick) polyacrylamide-starch twophase gel produces better resolved bands than starch or polyacrylamide alone.

A suitably buffered $7 \%$ polyacrylamide gel is prepared in a glass mould measuring $22 \mathrm{~cm} \times 15 \mathrm{~cm} \times$ $1 \mathrm{~mm}$ deep, the air being excluded with a glass plate during gelling. A strip measuring $12 \mathrm{~cm} \times 0.5 \mathrm{~cm}$ midway between the anode and cathode is removed by cutting around a glass strip of the same dimensions. The resulting cavity across the gel is carefully filled with $7 \%$ buffered starch gel. The samples are introduced into the starch phase, soaked on pieces of cotton thread or Whatman filter paper $1 \mathrm{~cm}$ long. Horizontal unidimensional electrophoresis is carried out under the appropriate conditions, with a cooling plate.

Other large-pore gels were tried in place of starch, but the results proved to be inferior. The running of the enzyme from the large-pore starch gel into the smaller-pore polyacrylamide gel results in the bands of activity concentrating at the interphase and running into the polyacrylamide as sharply resolved bands.

This technique has proved particularly effective in the study of the $\mathrm{C}_{5}{ }^{+}$phenotype of pseudocholinesterase (Harris, Hopkinson, Robson \& Whittaker, 1963; Robson \& Harris, 1966). The serum samples were diluted $1: 1$ with gel buffer $(0.125 \mathrm{M}$-succinic acid-0.147 M-tris, $\mathrm{pH} 4.8$ ) and run overnight (16h) at $7 \mathrm{~V} / \mathrm{cm}$ with a tank buffer of $0.05 \mathrm{M}$-citric acid adjusted to pH 4.8 with $40 \%$ sodium hydroxide. The zones of pseudocholinesterase activity were localized about $2 \mathrm{~cm}$ towards the anode by means of an agar overlay containing the reaction mixture (Stern \& Lewis, 1962).

After storage of the serum samples at $-20^{\circ} \mathrm{C}$ for a few weeks, slow-running 'storage' bands developed behind the $\mathrm{C}_{4}$ band in the $\mathrm{C}_{5}-$ type and behind the $\mathrm{C}_{5}{ }^{+}$band in the $\mathrm{C}_{5}{ }^{+}$type. These were removed by adding 2-mercaptoethanol to the diluted serum samples to a final concentration of 1 part in 500 .

Under these conditions polymorphic variants of adenylate kinase can also be clearly detected (Fildes \& Harris, 1966) on the same plate, but in a position cathodic of the origin.

This technique is also being successfully used on dried bloodstains at this laboratory.

Fildes, R. A. \& Harris, H. (1966). Nature, Lond., 209. 261. Harris, H., Hopkinson, D. A., Robson, E. B. \& Whittaker M. (1963). Ann. hum. Genet. 26, 359. 